\title{
Application of Geological Modeling Technology in 110 Block of Changchunling Oilfield*
}

\author{
Yidan Liu ${ }^{1}$, Jun Xie ${ }^{2}$, Ningning Meng ${ }^{2}$, Weihua $\mathrm{Li}^{2}$ \\ ${ }^{1}$ China University of Petroleum, Qingdao Shandong, 266590 \\ ${ }^{2}$ Shandong University of Science and Technology, Qingdao, Shangdong 266590 \\ ning0536@163.com
}

\begin{abstract}
The 110 is an ascertained but undeveloped block in Changchunling area. It is affluent in geological reserves, and has greatly development potentiality. This paper use the software of Petrel to establish three-dimensional fine modeling which include structural models, porosity models and permeability models. The model has the grid size of $20 \times 20 \mathrm{~m}$ in the plane. These provide the geological basis for the next program of enacting efficient development plan of 110 block.
\end{abstract}

Index Terms - Changchunling oilfield, undeveloped block, geological modeling, structural model

\section{Introduction}

With the rapidly development of computer, threedimensional modeling technology of petroleum reservoir has been the prime methods of petroleum industry making reservoir description[1]. three-dimensional quantitation geology modeling of the reservoir can reflect the characters of distribution and regularities of variation in reservoir geology space attribute. That provides geology basis for petroleum pool development ${ }^{[2]}$.We can see from the core of rock experimental analysis in this field that 110 block reflect the features of low tempreture, low pressure and high waxcontent. Moreover, 110 block is the typical representative of undeveloped one of Changchunling oilfield. Throught slecting optimizational develop scheme and design parameter of reservoir engineering for 110 block, we can arrive at the aim of gradually developing Changchunling oilfield. The paper is based on upon the existed well data to make reservoir threedimensional fine geological modeling, and preliminary understanding the reservoir structure of this block, also supplying the geological base for efficiently rational developing this Reservoir.

\section{Geological Characteristic}

Chang 110 block locates in the west horseblock of Changchunling, the top structure form of Quan 4 Formation is fault nose structure which is small-scale inclining southwest, this region develops two pieces of almost vertical faults, and these extend $3 \sim 5 \mathrm{~km}$, fault throw is $40 \sim 70 \mathrm{~m}$. From the data of accomplished wells drilling, the oilfield type of research area is lithological Structural Reservoir. The depth of reservoir varys between $210 \mathrm{~m}$ and $350 \mathrm{~m}$. The Sandstone thickness of average single well is $35.9 \mathrm{~m}$, net pay is $8.6 \mathrm{~m}$; from the rmometric and manometric material, we can understand the central tempreture of this reservoir is $20.5^{\circ} \mathrm{C}$, the pressure is 2.63MPa.

\section{Structural Model}

Structural model reflects the special framework of reservoir, namely the reservoir structural model of threedimensional space form of the inner reservoir Geologic Face, including fault model and Layer Model. This time modeling establish the grid system in plane that the plane grid size is $20 \times 20 \mathrm{~m}$, longitudinally it is divided into 25 zones according to single layer, forming $75 \times 55$ plane grid system, threedimensional grids up to 103125 , Fig. 1 and Fig.2 are respective structure model and panel map of research area.

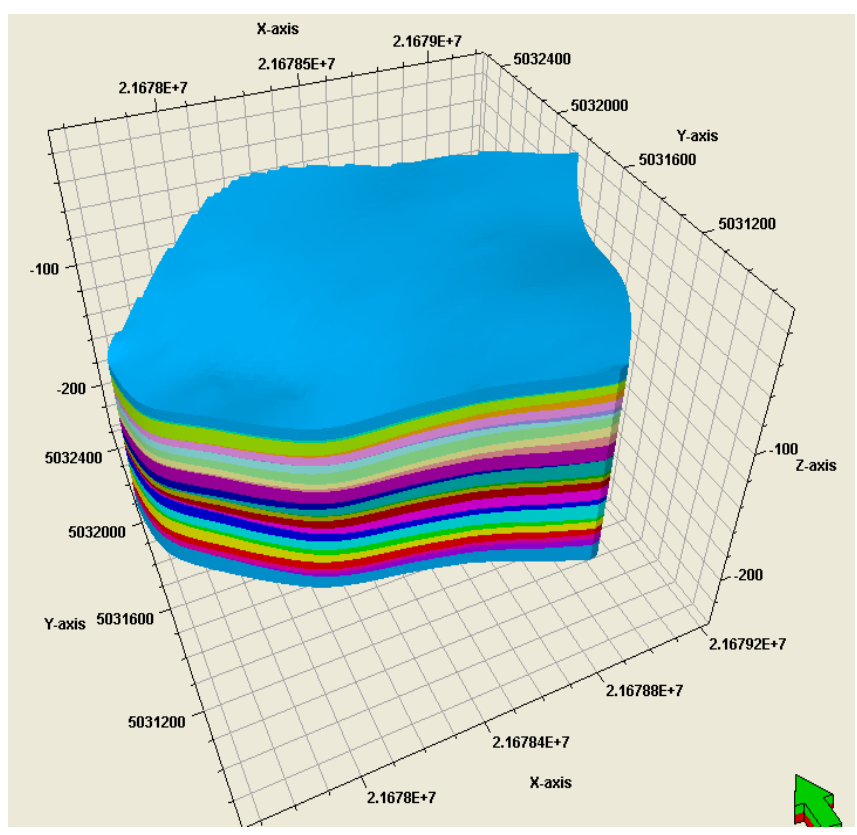

Fig.1 schematic diagram of structure model in 110 block 


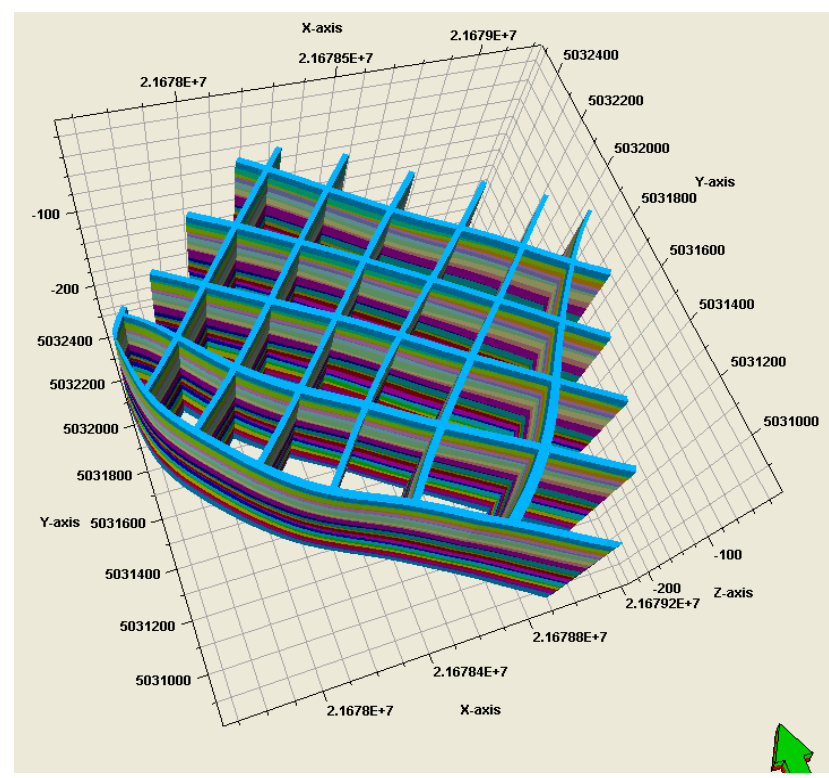

Fig.2 panelmap of structure model in Chang Chang 110 block

\section{Attribute model}

Lithofacies-controlled model finally aims at establishing parameter models which can exactly reflect porosity, permeability under the earth and the special distribution of effective reservoir[4]. Attribute model needs analyse variogram and makes Prior Choice of Stochastic Modeling, using the method of sequential Gaussian simulation method which bases on collocated cokriging establishs Porosity model and permeability model[5][6].

Porosity model This area, the Sediments of Quan 4 Formation are primaryly fine sandstone and especially fine sandstone, basically belong to mesopore- moderate permeability reservoir. Physical property of reservoir is relatively good,the average porosity is $24.6 \%$, among which porosity of the second, the fifth,the seventh majory single layers and so forth is comparatively big,up to about $27 \%$. The data analysis is made respectively according to different single layer and different Sedimentary micro Facies. Above basing on the result of data analysis and acquired variogram models, regarding sedimentary microfacies as the control conditions, to establish porosity model sphase-controlled[4]. Fig.3 and Fig.4 are respectively porosity model of Chang 110 block and panelmap.

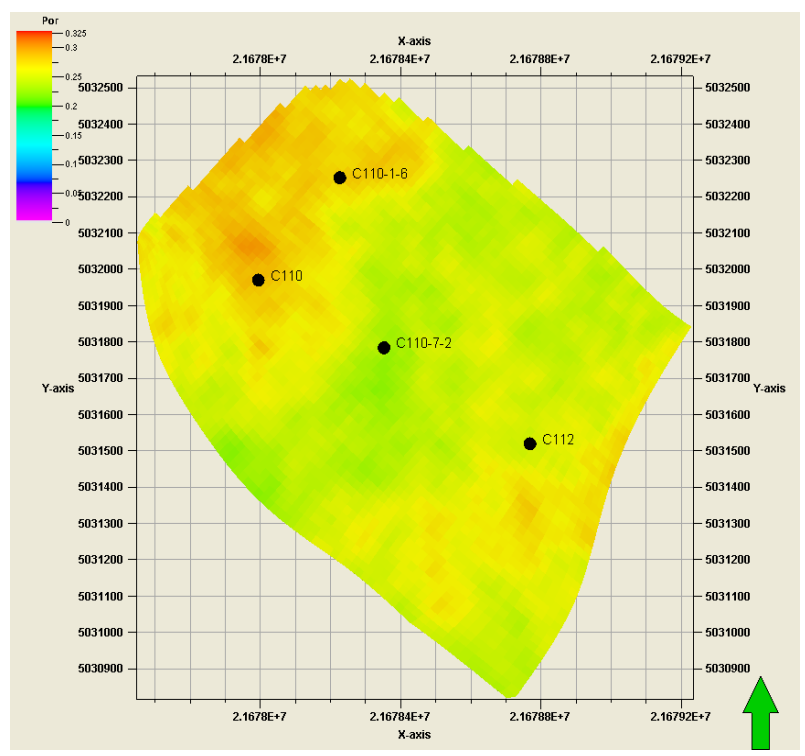

Fig. 3 planar graph of porosity model in Chang 110 bloak

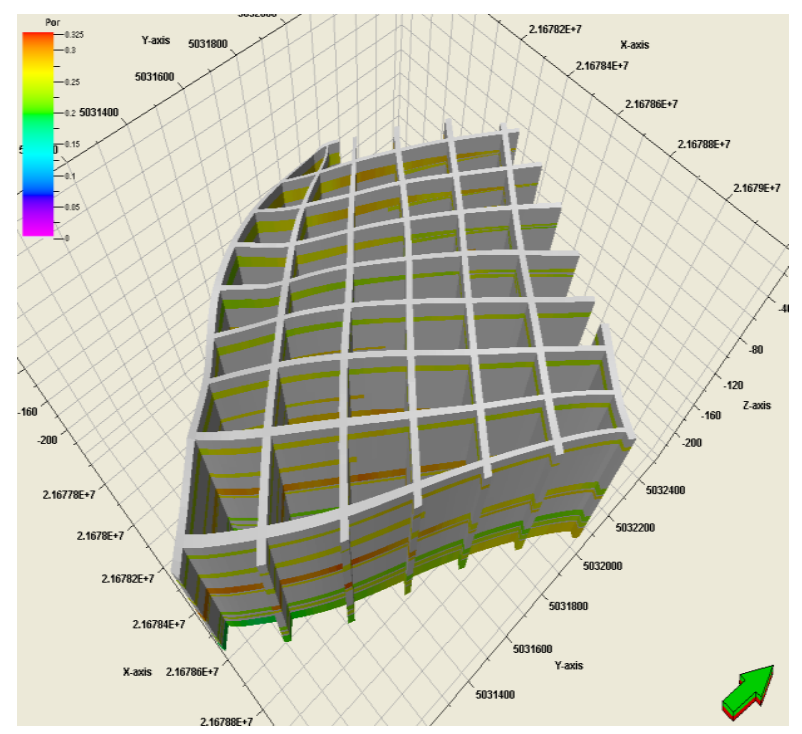

Fig. 4 panelmap of porosity model in Chang 110 bloak

Permeability model The physical distributions of the area are directly controlled by the distribution of sedimentary facies, the charting trends of porosity and permability every layer both are similar to the character of the charting trends of sands' thickness, that is, porosity and permability are greatly relative with sands' thickness or the types of sedimentary microfacies, the average vulue of permability is $138.7 \times 10^{-}$ ${ }^{3} \mu \mathrm{m}^{2}$.The permability of majory layers such as the second, fifth, seventh, thirteenth is high, up to about $270 \times 10^{-3} \mu \mathrm{m}^{2}$. Fig.5 and Fig.6 are respectively permability model and the panelmap of permability for Chang 110 block. 


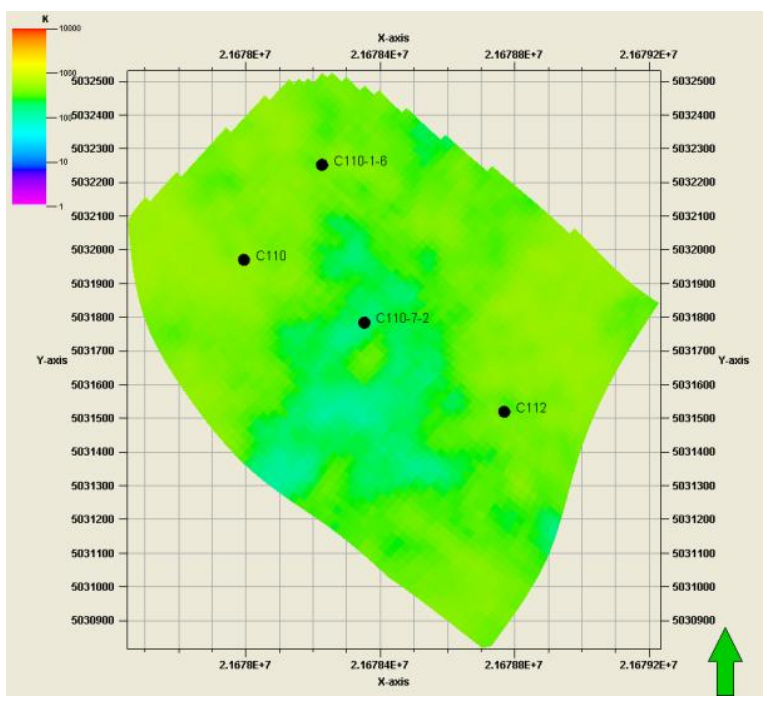

Fig. 5 planar graph of permability model in Chang 110 block

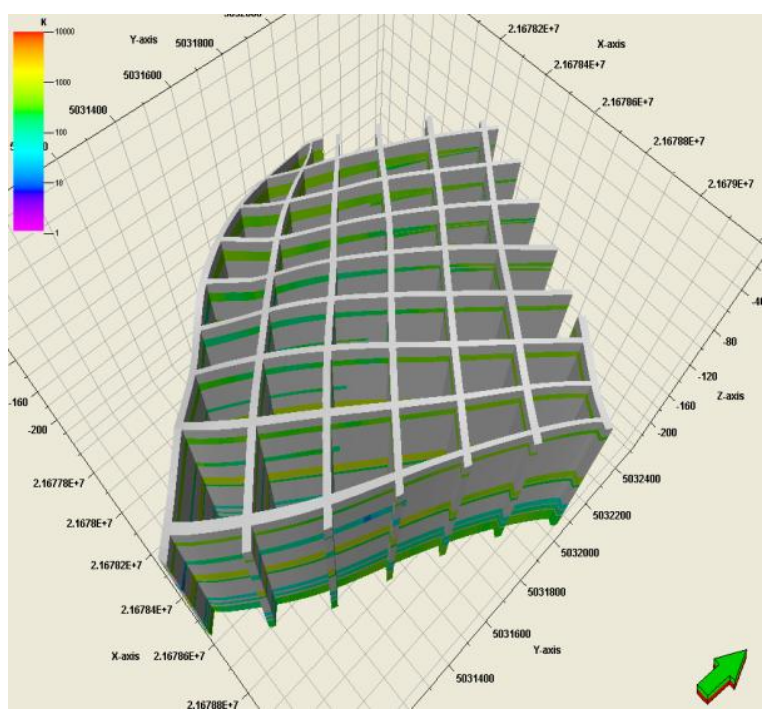

Fig. 6 panelmap of permability model in Chang 110 block

\section{Calculation of Model Volume}

One of the purposes to reservoir model is to calculate the volumes and geological reserves of oil and gas the for study area according to having been established three- dimensional reservoir models[6]. Making use of property models for Chang 110 block, such as structural models, porosity, permeability, oil bearing saturation, N/G and so on, and using the parameters of reservoir and fluid in this area, such as oil volume factors, oil density and so forth. The geological reserves of Chang 110 block get $175.3 \times 10^{4} \mathrm{t}$ through calculation of resvers. From the result of resver distribution, the resvers of Chang 110 block mainly concentrate in majory layers such as the second, fifth, seventh, thirteenth and so on.

\section{Conclusions}

(1) With the software, Petrel, and adopting the reasonable modeling methods, we have established three- dimensional visualization models for study area, including Layer Models ,fault models and phase-controlled attribute models, supplying dependable geological models for numerical simulation of reservoir.

(2) Based on having established reservoir models and distribution of fluid, through calculation, we received the petroleum geology reserves of Chang 110 block to $175.3 \times 10^{4} \mathrm{t}$.

\section{References}

[1] Song Haijing, Hu Mingyi. Date interface technique on petro software and geological datebase. Journal of Oil and Gas Technology (J. JPI), 2009, 31(3): 217-218

[2] Li Yu, Yang Changqing. Strategy of reservoir geological modeling and application of technical method. Journal of Oil and Gas Technology (J. JPI), 2009, 31(3): 30-36

[3] Xie Jun, Meng Ningning, Yu Jiangtao, Lin Peng. The Research of Fine Geological Modeling for a Single Well in VII lower unit of Shuanghe Oilfield. 2009 Second International Conference on Future Information Technology and Management Engineering: 555-558

[4] Pan Shaowei1, Yang Shaochun and Yang Bai. Application of faciescontrolled modeling technology to the fault-block Z2in Jiangsu oilfield. NATURAL GAS GEOSCIENCE, 2009, 20(6): 935-940

[5] Yang Wei, Li Lingling, Gao Junheng. Application of random modeling technique in reservoir description in Biqian10 area. Inner Mongolia Petrochemical Industry, 2010, (8): 30-31

[6] Yu Jiangtao, Xie Jun, Meng NingNing, Lin Peng. 3D geological modeling in Chang109 block of Changchunling oilfield. Advanced Research on Industry, Information System and Material Engineering: 1891-1894 